\title{
Digitally Enabled Advanced Services: A Socio-technical Perspective on the Role of the Internet of Things (IoT)
}

\author{
Andreas Schroeder, Parikshit Naik, Ali Ziaee Bigdeli, and Tim Baines
}

\author{
The Advanced Services Group, Aston Business School Aston University \\ Birmingham, B4 7ET, UK.
}

\begin{abstract}
Purpose - The purpose of this study is to investigate how the Internet of Things (IoT) contributes to manufacturers' advanced services development and delivery. In order to better understand the creation of these IoT contributions, the study adopts a sociotechnical research perspective, which expands the scope of the investigation and integrates the technological, information and social factors that enable these IoT contributions.
\end{abstract}

Methodology - A multiple-case research method was employed to investigate the IoT contribution scenarios of 15 manufacturers who offer advanced services, and to examine their dependence on other non-IoT factors, using thematic analysis.

Findings - The analysis identified five advanced services value propositions, which are enabled by nine 'IoT-enabled IS artefacts' that specify the distinct interactions between the technological, information and social subsystems supporting the manufacturers' advanced services value propositions.

Originality - The study advances servitization research by demonstrating that IoT technology on its own is insufficient for the creation of the IoT contributions. It shows, instead, the need for close interactions with a diverse range of other factors which are often not considered when developing an IoT strategy. The study also introduces the IS artefact notion as a unit of analysis that constitutes an alternative to the commonly adopted techno-centric perspective used to conceptualise IoT contributions. The study and its findings add to the development of a socio-technical perspective on the IoT in advanced services, and thereby suggests a number of theoretical and practical implications.

Keywords: IoT, advanced services, servitization

Ackknoledgement - This work was supported by Economic and Social Research Council (ESRC) Grant Ref ES/P010148/1: Pathways towards Servitization: A trans-national study of Organisational Transformation, EPSRC Grants Ref EP/K014064/1, EP/K014072/1, EP/K014080/1: 'Transforming the adoption of Product-Service Systems through innovations in applied gaming technology', and BBSRC Grant Ref BB/S020993/1: Next Generation Rice Processing. 


\section{Introduction}

The Internet of Things (IoT) is increasingly recognised as a core enabler of the advanced services that manufacturers offer (Ardolino et al., 2018). Several authors describe the IoT technology as a prerequisite for advanced services (Rymaszewska, Helo, \& Gunasekaran, 2017; Spring \& Araujo, 2017), while others propose advanced services as the business model for manufacturers to monetise their IoT investments (Kamp \& Parry, 2017; March $\&$ Scudder, 2019). Although the extant literature recognises the importance of IoT technology for the development and delivery of advanced services, a full appreciation of its specific contributions remains limited. A detailed and comprehensive understanding of both technical and non-technical contributions, as well as the mechanisms that enable them, are critical to ensure impactful research and support insightful management initiatives (Hong, Chan, Thong, Chasalow, \& Dhillon, 2014).

The IoT, in its simplest form, is defined as 'a network of items - each embedded with sensors - which are connected to the Internet' (Minerva, Biru, \& Rotondi, 2015, p. 10). At the root of the IoT is a convergence of product digitalisation and ubiquitous communication technology, which together create unprecedented levels of connectivity and the ability to observe and actuate products remotely (Cagliano, Canterino, Longoni, \& Bartezzaghi, 2019). With the IoT connecting increasing numbers of digitalised products, it has become a major source of data and intelligence in relation to product use and availability, which could, ultimately, improve efficiency and productivity (Yang et al., 2017). This would also expand the organisations' traditional data resources (e.g. ERP, SCM) and increase their digital capabilities (e.g. Big Data Analytics) (Suppatvech, Godsell, \& Day, 2019; Tao \& Qi, 2017).

The widespread adoption of the IoT is based on raised expectations of substantial economic benefits (Edquist, Goodridge, \& Haskel, 2019), with manufacturers in particular anticipating new growth opportunities from their IoT initiatives (Economist Intelligence Unit, 2020). Yet recent evidence shows that IoT initiatives in more than $30 \%$ of firms have failed to create the anticipated benefits (Microsoft, 2019); notably, the issues causing such failures are often non-technological (Cisco, 2017). These findings highlight the challenge of realising the opportunities that IoT offers, and critically question the necessary scope of inquiry to understand and manage its contributions.

These questions concerning the appropriate scope of inquiry become particularly important in the context of servitization and advanced services. Advanced services describe complex value propositions whereby manufacturers offer performance outcomes to their customers by providing product-service bundles, instead of just products (Baines \& Lightfoot, 2013; Ziaee Bigdeli et al., 2018). By integrating IoT technology into product offerings, manufacturers can monitor the performance of their products within the context of their service commitments. The servitization literature has emphasised the importance of the connectivity enabled by the IoT technology for advanced services, since it supports the manufacturer's predictive maintenance and service prototyping capabilities (Opresnik \& Taisch, 2015; Zancul et al., 2016).

Using the IoT to enable advanced services is not just a technical challenge, but also a relational one. The core contribution of the IoT in an advanced services context is premised on a customer authorising the manufacturer to closely monitor its product as it forms an integral part of the customer's business - a concession which requires trust in the manufacturer-customer relationship (Suppatvech et al., 2019). Industrial companies 
are naturally hesitant to share data that may reveal operational details and provide their suppliers with negotiation leverage (Schroeder, Ziaee Bigdeli, Galera Zarco, \& Baines, 2019). Therefore, the importance and implications of these relational challenges in terms of the manufacturer's ability to utilise the IoT in an advanced services context point to two critical gaps in the literature.

The first gap refers to our limited understanding of the interdependencies between the technical and non-technical aspects that enable the IoT contributions. For example, Fischer et al. (2020) emphasise the importance of a trust in the manufacturer-customer relationships to ensure that the opportunity the IoT offers can be realized. Conversely, Boehmer et al. (2020) show how the IoT effectively creates trust-based environments which then enable the advanced services. While the servitization literature has started to recognise that non-technology factors are critical to enabling the IoT technology contributions (Suppatvech et al., 2019), understanding the specific roles and interdependence of these factors is crucial in the context of advanced services.

The second gap refers to our limited understanding of the way manufacturers should manage this diverse range of technology and non-technology factors to ensure that the opportunities the IoT offers to advanced services can be fully realised. For manufacturers, it becomes important to understand the scope of activities and resources (beyond the core IoT technology) that needs to be considered, and how their development and deployment should be aligned. The lack of such insights risks manufacturers seeking to advance their IoT technology deployment without having the non-technology factors in place that are required to realise its contribution in an advanced services context.

To address the abovementioned gaps, the present study investigates the following question: how does the IoT contribute to manufacturers' advanced services? We adopt a socio-technical research perspective (Kull, Ellis, \& Narasimhan, 2013), which expands the investigation from a focus on IoT technology to a focus on the social and organisational context, in which the contribution of the IoT technology is created (Land \& Hirschheim, 1983). The study draws on the IS artefact theory (Lee, Thomas, \& Baskerville, 2015) to develop a research framework that structures the identification of the specific contributions the IoT makes to advanced services, and conceptualises how the IoT technology, data resources and relational aspects enable these contributions. The framework is used to analyse the advanced services of 15 multi-national manufacturers.

The study identifies five distinct IoT-enabled advanced services value propositions and nine IS artefacts that specify the IoT contributions are identified in the analysis. It advances the research into servitization by clearly identifying the role of the IoT as an enabler of advanced services, and recognising the diverse resources and activities that facilitate this function. The study builds a socio-technical understanding of the contribution the IoT makes to advanced services.

Following the introduction, a focused review of the core aspects of advanced services is provided, and the literature exploring the IoT's contributions to them is examined. The IS artefact theory is subsequently introduced, and the notion of the 'IoT-enabled IS artefact' is conceptualised in the form of a research framework that guides the subsequent methodology and analysis. The paper concludes by discussing the research findings, their theoretical and practical implications, and the future research opportunities they may create. 


\section{Background and framework conceptualisation}

This section reviews the core aspects of advanced services and the role of the IoT before developing a framework that conceptualises the IoT from a socio-technical perspective.

\subsection{Manufacturer's advanced services and its required capabilities}

\section{Advanced services value propositions}

'Advanced services' specify a distinct range of value propositions, where manufacturers use product-service bundles to offer capabilities that create value for their customers (e.g. saving time; reducing costs and risks) (Baines \& Lightfoot, 2014; Sousa \& da Silveira, 2017). The advanced services notion is tightly linked to the servitization discourse, which captures the strategic and organisational transformation manufacturers require in order to be able to offer such product-service bundles (Baines, Bigdeli, Sousa, \& Schroeder, 2020). The notion is increasingly used to differentiate these complex product-service offerings from a manufacturer's base services (e.g. spare parts or tools to enable customers to maintain their products) or intermediate services (e.g. maintenance, repairs and overhaul, and helpdesk to support customers in maintaining the condition and functionality of their products) (Raddats, Kowalkowski, Benedettini, Burton, \& Gebauer, 2019; Ziaee Bigdeli et al., 2018).

The feature that distinguishes advanced services from base and intermediate services is a focus on supporting customers to achieve their goals, instead of supporting the products themselves. Musson, Baines, \& Bigdeli (2019) differentiate between advanced services value propositions that address the customers' (i) product use, (ii) business processes, or (iii) business models. When offering advanced services value propositions that support customers' product use, manufacturers seek to ensure their products provide the functionalities that customers require (e.g. availability, reliability and performance). Rolls Royce's 'power by the hour' model (Grubic \& Jennions, 2018) represents an example of such a product-use-focused value proposition, whereby customers (e.g. airlines) are offered the uninterrupted core functionality of its product (i.e. thrust), including availability guarantees.

Advanced services that target customers' business processes include value propositions that provide customers with performance and efficiency assurances on processes of which the product is a part. An example of this is the process compliance monitoring that a manufacturer may offer to its customers (Musson et al., 2019). In value propositions targeting customers' business models, manufacturers help their customers to offer new value propositions, in turn, to their own customers. Manufacturers, for example, may offer innovation support that enables their customers to develop new product lines.

\section{Capabilities for advanced services}

Recognising the distinct challenges that advanced services pose for manufacturers, a stream of research is emerging that investigates the capabilities - the firm's specific abilities to perform the required activities - that are critical for the development and delivery of advanced services (Jacobides \& Winter, 2012). Sousa and da Silveira (2017), for example, identify the importance of service design and co-creation capabilities to advanced services. Story et al. (2017) differentiate between the capabilities of advanced services in a multi-actor context, emphasising the importance of the manufacturers being able to balance product and service innovation, establish customer relations and coordinate third-party providers. Raddats et al. (2017) stress the importance of knowledge development and risk management capabilities, while Sjödin, Parida, \& Kohtamäki 
(2016) draw attention to mass service customisation and network management capabilities.

In order to conceptualise the range of capabilities that manufacturers require to develop and deliver advanced services, this study will draw on Chakkol et al.'s (2018) comprehensive capability framework. Their framework differentiates between five critical capabilities: Leverage offerings captures the manufacturers' operational and strategic capacity to modify their established product offerings and position it within an advanced services context; Consulting function describes the manufacturers' ability to move beyond their manufacturing knowledge and develop business expertise that represents a value proposition for their customers; Dissonance reduction represents the manufacturers' ability to mediate and maintain their customer relationships, including joint problem-solving and conflict resolution; Professional education captures the manufacturers' ability to foster and manage the critical advanced services expertise for themselves and their partners; and Strategic communication describes manufacturers' ability to effectively present their strategic intent and offerings. By mapping out the range of capabilities that manufacturers require to develop and deliver advanced services, the framework provides an opportunity to structure the analysis of the diverse range of IoT contributions.

\subsection{The Internet-of-Things and its role in Advanced Services}

As the IoT is commonly highlighted as one of the core enablers of advanced services (Ardolino et al., 2018), it is important to understand the precise nature of its contributions. To assess the current understanding of the contributions that the IoT provides, the servitization literature was examined in the form of a scoping review (Paré, Trudel, Jaana, \& Kitsiou, 2014), whose aim was to understand how the servitization literature captures (a) the advanced services aspects to which the IoT contributes, and (b) the range of activities and resources that enable the IoT contributions (see the Appendix for a description of the review method and detailed findings).

The review identified 14 publications that explicitly examine the IoT's contribution to advanced services. Their analysis identifies a variety of ways in which the IoT contributes to advanced services, including remote monitoring (Spring \& Araujo, 2017), predictive maintenance (Cortez \& Johnston, 2017) and process optimization (Löfberg \& Åkesson, 2018) (see Appendix). But the review also revealed that, in the majority of these publications, limited detail is provided on exactly how the IoT enables these contributions, and how they translate into the development and delivery of specific advanced services value propositions. Notable exceptions include March et al. (2019), who model the impact that IoT-enabled predictive maintenance creates for advanced services profitability through improved optimization of maintenance.

The review further identified significant differences in the range of activities and resources authors include in their analysis of the IoT contributions. The majority of publications centre on the IoT's core technological features and capabilities, which are conceptualised to directly and independently contribute to the advanced services (e.g. March \& Scudder, 2019; Spring \& Araujo, 2017). A smaller number of publications expand this investigative scope by taking a wider range of activities and resources into account, which also play a role in the creation of these IoT contributions; Several studies explicitly highlight how data-specific consideration (e.g. security) or analytical skills enable the IoT's contribution to the advanced services (e.g. Spring \& Araujo, 2017; Suppatvech et al., 2019). Two of the identified publications expand the investigative scope further by conceptualising social aspects as critical enablers of the IoT 
contributions. Fischer et al. (2020) specifically emphasise the critical role trust plays in the effective delivery of IoT-enabled advanced services. Boehmer et al. (2020), however, conceptualise the IoT as an enabler of trust, which then enables the advanced services.

Although the literature on servitization explicitly recognizes the IoT as a critical enabler of advanced services, insights surrounding its specific contributions and the understanding of the range of resources and activities that facilitate these contributions are still meagre. However, authors in the wider technology literature have already started to examine the creation of the IoT contributions by systematically expanding the investigative scope beyond the technology. Beier et al. (2020), for example, argue that a sole technology focus does not necessarily allow conclusions to be drawn in relation to the success or failure of an IoT initiative, and explicitly suggest that the IoT should not be investigated as a "single technology, but a sociotechnical concept in which technological, social and organizational aspects interact" (p. 12). Krotov (2017) and Sony and Naik (2020) contend that the adoption of a wider investigative scope is critical to designing and understanding business models that capitalize on the IoT opportunities, since the "implementation success and sustainability of the design will also rely on appreciating socio-technical features" (Sony \& Naik, 2020, p. 2). An expanded investigative scope is thus required to develop a comprehensive understanding of the diverse contributions the IoT creates for the advanced services business model.

\subsection{Research framework}

To enable a comprehensive investigation into how the IoT contributes to advanced services, we developed a framework that systematically expands the consideration of the IoT contribution from a socio-technical perspective. We use Lee et al.'s (2015)IS (information systems) artefact theory as the theoretical basis for the framework development. Lee et al. (2015) define an 'IS artefact' as (i) a human-designed system (i.e. artificial thing), which (ii) can be characterised by its functional utility, and (iii) is enabled by the inseparable interaction between technology, information and social subsystems. By adopting an IS artefact perspective to explore the contribution a technology provides, the attention shifts from a focus on the technology as a utility creator to a focus on the interaction of the technology-, information- and social-subsystems, creating the utility together (Iivari, 2017; Lowry, Dinev, \& Willison, 2017). This concept of the IS artefact proposes that the utility of a technology is affected more by the context of its use than its technical features (Avgerou, 2001). Therefore, the theory provides a structured, sociotechnical approach to explain contributions from the contextual use of a technology (Land \& Hirschheim, 1983; Lowry et al., 2017).

We use this structured approach to conceptualize the 'IoT-enabled IS artefact' and investigate its contribution to advanced services. Following Lee et al. (2015), the conceptualisation of the 'IoT-enabled IS artefact' requires, first, the specification of the functional utility, which benefits the particular advanced services value proposition; and, second, the identification of the subsystems that (together with the IOT) create the utility (see figure 1). 


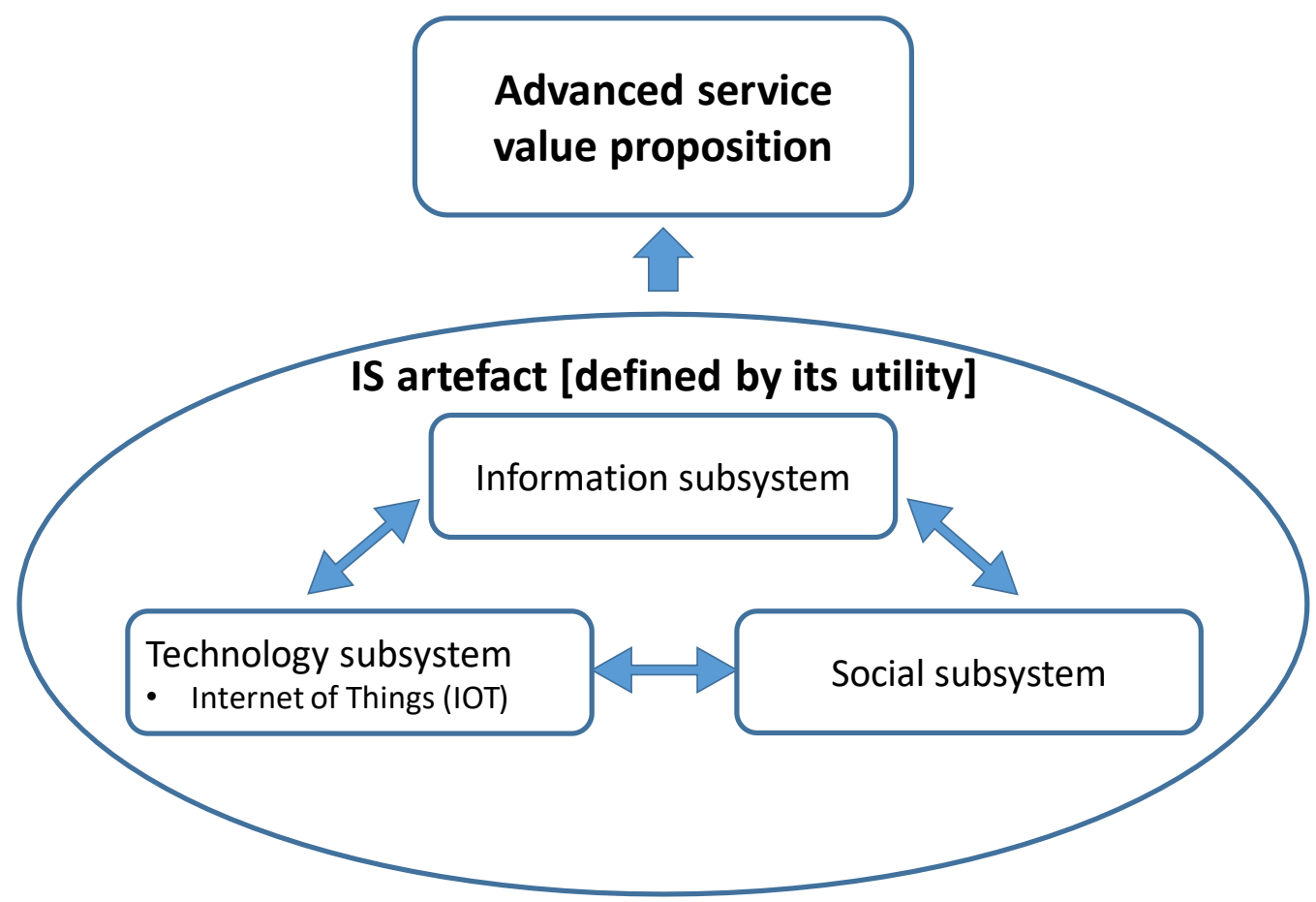

Figure 1. The 'IoT-enabled IS artefact'

The specification of the functional utility is critical to understanding the diverse contributions the IoT can make to the manufacturer's development and delivery of its advanced services. Manufacturers may offer a number of value propositions, each requiring one or more functional utilities to support their realization (Frank, Mendes, Ayala, \& Ghezzi, 2019). For instance, a manufacturer offering 'product uptime' as a value proposition will aim to 'reduce the likelihood of a repair', but also 'speed up the repair' - two separate IoT-enabled functional utilities that are already highlighted in the servitization literature (Suppatvech et al., 2019).

The IoT forms part of the artefact's technology subsystem. From a research perspective, it becomes important to determine how the IoT (and other analytics and simulation technologies) creates the functional utility, and how it interacts with the other subsystems to create the required utility. Further, the wider literature recognizes the fact that data resources (e.g. product and user data) are important in the creation of these IoT contributions (Luz Martín-Peña, Díaz-Garrido, \& Sánchez-López, 2018; Opresnik \& Taisch, 2015), but in the context of IS artefact theory, it becomes important to underscore their enabling roles. The IS artefact notion also draws attention to those relational aspects (in the form of the social subsystem) that are required to create the IoT contributions. Although the servitization literature starts to acknowledge the importance of these social aspects (e.g. trust) in creating the IoT contributions (Boehmer et al., 2020; Fischer et al., 2020), their specific role, as well their contribution to the information and technology subsystems, needs to be understood.

The proposed framework conceptualises the diverse subsystems that enable the IoT to produce the functional utilities that manufacturers require to design and deliver their advanced services value propositions. It provides an opportunity to systematically investigate the contribution the IoT makes to advanced services. 


\section{Research method}

A multiple-case research method was selected to investigate the IoT's contribution to the manufacturers' advanced services (Miles \& Huberman, 1994; Yin, 2005). The method enables researchers to theorise on the rich experiences of organisations exploring rapid technological changes (Dubé \& Paré, 2003), provides detailed illustrations of complex phenomena to strengthen analytical generalisations and by using multiple cases enhances the external validity of the findings (Yin, 2005). The application of the case research method is characterised by the specific data collection and analysis strategies employed.

\subsection{Data collection}

The core data collection objective was to capture detailed accounts of advanced services value propositions in which the IoT plays a significant role. To support external validity of the research and its findings a case selection strategy was employed to identify manufacturers which: (i) have notable experience of IoT-enabled advanced services development and delivery; (ii) operate internationally; and (iii) trade in a business-tobusiness context. The selection criteria were established to ensure that the case organisations offer valuable insights for further analysis, operate at scale, and align with the industrial focus of servitization theory (Baines \& Lightfoot, 2014). A wide range of secondary data sources (e.g. websites, brochures, news articles) were used to identify candidate cases. To gather interest in participation and verify eligibility, managing directors (or equivalent) were approached through emails and/or phone calls. As a result, 15 manufacturers $^{1}$ from a diverse range of industries agreed to participate in this study. An overview of the selected cases is provided in Table 1.

The case data was collected in the form of semi-structured interviews with senior decision-makers providing detailed insights into their organisation's advanced services and IoT contribution scenarios. These interviews were complemented by insights from secondary data sources. For the first case (case [1]), interviews with five representatives were carried out in order to obtain comprehensive insights into the wider context of IoTenabled advanced services (Eisenhardt, 1989). The insights gained from these first interviews have suggested that a few key representatives within the manufacturers have sufficient exposure to both the IoT and advanced services context to provide the details required. Hence, for the rest of the cases, it was deemed sufficient to interview one or two key experts, which is consistent with other studies drawing on expert interviews (Herterich, Uebernickel, \& Brenner, 2015; Long, Blok, \& Coninx, 2016; Matthyssens \& Vandenbempt, 2008). As the responsibilities for developing and delivering advanced services is not consistently allocated within the same unit in these organisations, the key experts were found in different areas (see Table 1).

Table 1. Case organisations

\begin{tabular}{|c|l|l|}
\hline Case & Type of Firm & Role \\
\hline$[1]$ & Heavy equipment manufacturer & CEO \\
& & Director IoT \\
\cline { 3 - 3 } & & Director Finance \\
\hline & & Service Director \\
\cline { 3 - 3 } & & Head of Service Marketing \\
\hline$[2]$ & Heavy equipment manufacturer & Director Global Services \\
\hline$[3]$ & Hospital equipment manufacturer & VP Global Services \\
\hline
\end{tabular}

\footnotetext{
${ }^{1}$ The study exceeds Eisenhardt's (1989) recommendation of ten case organisations.
} 


\begin{tabular}{|l|l|l|}
\hline & & Director, Predictive Maintenance \& Intelligence \\
\hline$[4]$ & Heavy equipment manufacturer & Service Manager \\
\hline$[5]$ & Hospital equipment manufacturer & Senior Service Manager \\
\hline$[6]$ & Production equipment manufacturer & Customer Service Manager \\
\hline$[7]$ & Office equipment manufacturer & Technical Service Operations Manager \\
\hline$[8]$ & Production equipment manufacturer & General Manager \\
\hline$[9]$ & Hospital equipment manufacturer & Director Solutions Management (2 interviews) \\
\hline$[10]$ & Production equipment manufacturer & Head of Technical Support Equipment \\
\hline$[11]$ & Production equipment manufacturer & Director Services \\
\hline$[12]$ & Office equipment manufacturer & Head of Product Related Services \\
\hline$[13]$ & Production equipment manufacturer & Head of Business Development Services \\
\hline$[14]$ & Facility management equipment manufacturer & Service Director EMEA \\
\hline$[15]$ & Production equipment manufacturer & Director Global Strategic Sales \\
\hline
\end{tabular}

The interviews focused on three areas: (i) the manufacturer's advanced service offerings, in which the corresponding questions focused on the range of the offerings, their specific details (e.g. KPI's contractual obligations), and the experiences with the delivery of these offerings; (ii) the IoT contributions to these offerings, in which the questions focused on the specific benefits that the IoT provides to these advanced service offerings and how these offerings could be provided without the IoT; and (iii) the factors that play a role in the creation of these IoT contributions, where the interview questions focused on the additional activities and resources that enable the IoT contribution and the experiences of their development and integration. The detailed interview protocol was developed and tested with colleagues involved in advanced services advisory activities.

The interviews were conducted by a pair of researchers in order to maintain clarity and consistency in the process, and to ensure dependability (Guba \& Lincoln, 1994). A total of 21 interviews (lasting between 30 and 120 minutes) were conducted, recorded and transcribed (verbatim), and used as the primary data for further analysis. These were complemented by secondary data, which included field notes the researchers took during the interviews and additional document material (provided or separately sourced). The secondary data sources were used to supplement the interview data, with additional details on the service offerings, thus expanding the scope and depth of data available for analysis.

\subsection{Data analysis}

The data analysis used the IoT-enabled IS artefact framework to identify the range of contributions the IoT provides to advanced services and the resources and activities that enable them. The analysis was conducted by two researchers following Braun and Clarke's (Braun \& Clarke, 2006) established thematic analysis steps: (1) data familiarization, (2) initial code generation, (3) theme development, (4) refinement, (5) theme designation. Thematic analysis identifies the themes that emerge as being important to the description and characterisation of a phenomenon, and has formed the basis of a variety of comparable studies (e.g. Raddats et al., 2017; Raja, Chakkol, Johnson, $\&$ Beltagui, 2018). These phases of thematic analysis were first used to identify critical advanced service value propositions, before focusing on the identification of the corresponding IoT-enabled IS artefacts.

\section{Identification of advanced services value propositions}

The objective for identifying the advanced services value proposition was to establish the unit of analysis, for the purposes of the subsequent examination of the IoT contribution. Hence, the case data was analysed using the thematic analysis steps to identify value propositions that (i) are based on a product-service bundle and (ii) where the IoT plays a demonstrable enabling role. 
In order to familiarize themselves with the case data, the researchers reviewed the transcripts, field notes and documents to understand the range of IoT-based advanced service offerings the case organizations provide. This was followed by a data-driven initial coding process to capture and label the details of the advanced service offering. The focus was to dissect the individual offerings and consistently categorise their core components across the different cases. The initial coding followed an iterative process, with the two researchers engaging in frequent discussions to develop an exhaustive categorisation of the advanced service offering across the case data where it was felt that no new codes would add to the understanding of the advanced service value proposition (theoretical saturation).

The subsequent theme development step focused on collating the codes for each case into value proposition descriptions, which capture their essence and distinguishing factors. The following theme review stage involved the consolidation of the value propositions identified across the cases to ensure consistency in their descriptions. Only value propositions that were offered by more than three case organisations were considered for further analysis to ensure the wider applicability of the research. The concluding theme designation step focused on the formulation of clear labels and definitions of the identified value propositions to guarantee their consistent application and facilitate their adoption by other researchers.

\section{Identification of IoT-enabled IS artefacts}

The analysis of the 'IoT-enabled IS artefacts' was focused on the identification of the specific utility the IoT provides to the previously identified advanced service value propositions and the establishment of the specific subsystems that enable the IoT's effective contribution.

Following the identification of the advanced services value propositions, the researchers were already familiar with the case data and could engage with the comparable datadriven initial coding process (comparable to the above). The coding process focused simultaneously on two levels of analysis: the level of the utility and the level of the activities and resources that enable the IoT contributions. The coding of the utility concentrated on capturing and labelling the range of contributions that the IoT provides, while the coding of the activities and resources centred on capturing and labelling the additional technologies, information resources and those social relationships that critically enable the creation of the utility. The researchers sought to dissect the description of the IoT contribution scenarios in order to categorise their components according to the advanced service value proposition.

The theme development and review focused on developing detailed descriptions of the utilities and the enabling subsystems that are consistent across the entire range of value propositions encountered. The development of the utility theme was focused on clearly describing the contributions that the IoT, with its enabling subsystems, provide to the value propositions. The development of the subsystem themes was focused on mapping out and clearly labelling the range of subsystems that play a role in the creation of the IoT contributions. The theme designation focused on the formulation of labels and definitions but also on grouping the identified activity and resource themes as technology subsystems (focusing on the technical components), information subsystems (focusing on information and instantiations) and social subsystems (focusing on the social relationships or interactions) that enabled the IS artefact's utility.

The steps of data collection and analysis were aimed at enhancing the rigor of the study. The use of a systematic research protocol and the involvement of two researchers 
throughout these steps helped to enhance the reliability of the research. The development of a theoretically grounded research framework and the use of multiple cases has contributed to the internal validity of the research (Gibbert, Ruigrok, \& Wicki, 2008; Voss, Tsikriktsis, \& Frohlich, 2002) Whilst the construct validity was ensured by the application of theory-based constructs and clear definitions of codes and themes, the external validity of the research was addressed by the clear case selection criteria and by corroborating the findings across a diverse range of cases (Yin, 2005).

\section{Findings}

The presentation of the findings first outlines the advanced services value propositions encountered in the case organisations, before delineating the IoT-enabled IS artefacts that support their development and delivery.

\subsection{Advanced services value propositions}

The analysis of the case data that was drawn from the manufacturers identified five advanced services value propositions that utilize the IoT technology. Each of the value propositions was offered by at least four case organisations, indicating their prevalence among servitized manufacturers (see Table 2). Three of the identified propositions focus on supporting the product in use; by offering these value propositions, manufacturers ensure their product provides the functionalities their customers require in order to achieve their goals. Two value propositions focus on supporting the customers' business processes; manufacturers are offering to optimise the product-related administrative burden or business processes of their customers.

Table 2. Advanced services value propositions identified

\begin{tabular}{|c|c|c|}
\hline $\begin{array}{l}\text { Product-focused value } \\
\text { proposition }\end{array}$ & Description of value proposition & Cases \\
\hline Product uptime & $\begin{array}{l}\text { Customers are offered a commitment to minimise the } \\
\text { occurrence and extent of unplanned product downtime; } \\
\text { this reduces interruptions to continuous product use }\end{array}$ & $\begin{array}{l}{[1],[3],[5]} \\
{[6],[9],[11]}\end{array}$ \\
\hline $\begin{array}{l}\text { Continuous } \\
\text { consumables/wear } \\
\text { part availability }\end{array}$ & $\begin{array}{l}\text { Customers are offered continuous access and availability of } \\
\text { essential consumables; this reduces the risk of product-use } \\
\text { disruptions, minimises stock-management efforts and } \\
\text { stock-piling costs }\end{array}$ & $\begin{array}{l}{[3],[5],[7],} \\
{[9],[11],[13]} \\
{[14]}\end{array}$ \\
\hline Product usage support & $\begin{array}{l}\text { Customers are offered support with the appropriate usage } \\
\text { of their product; this reduces the risk of misuse or } \\
\text { inefficient use of the product }\end{array}$ & $\begin{array}{l}{[1],[2],[4]} \\
{[8],[9],[10]} \\
{[11],[12],[15]}\end{array}$ \\
\hline $\begin{array}{l}\text { Business-focused } \\
\text { value proposition }\end{array}$ & Description of value proposition & Case \\
\hline $\begin{array}{l}\text { Reducing the } \\
\text { customers' } \\
\text { administrative burden }\end{array}$ & $\begin{array}{l}\text { Customers are offered a commitment to provide the } \\
\text { administrative function associated with the use of the } \\
\text { product; reduces efforts and improves the quality of } \\
\text { administrative requirements }\end{array}$ & $\begin{array}{l}{[1],[3],[14],} \\
{[12]}\end{array}$ \\
\hline $\begin{array}{l}\text { Optimising the } \\
\text { customers' business } \\
\text { processes }\end{array}$ & $\begin{array}{l}\text { Customers are offered specific and targeted advice to } \\
\text { identify inefficiencies in their business processes related to } \\
\text { the product; reduces inefficiencies in product use }\end{array}$ & $\begin{array}{l}{[1],[5],[9],} \\
{[12]}\end{array}$ \\
\hline
\end{tabular}

It is important to note that the manufacturers were found to offer these propositions either individually or as a bundle. Case [1], for example, offers product uptime and the reduction of the customer's administrative burden within a single advanced services package. However, case [9] was found to offer product uptime and continuous consumables/wear 
part availability as separate deals. For the purpose of the study, the identified advanced services value propositions formed the unit of analysis to investigate the IoT-enabled IS artefacts which support them.

\subsection{The IoT-enabled IS artefacts}

The analysis of the advanced services value propositions identified nine distinct 'IoT enabled IS artefacts' that provide them with critical support. Hence, the IoT technology (through the artefact) was found to provide nine distinct functional utilities that support one or more value propositions (see Table 3 below for a summary). The artefacts were named based on the utility they provide and grouped into those that leverage productservice offerings, develop consulting functions, reduce dissonance or create and disseminate knowledge (following Chakkol et al., 2018).

\section{Leverage product-service offering}

Four of the identified IOT-enabled IS artefacts were found to directly support the manufacturers in leveraging their advanced service value propositions.

\section{Maintenance optimisation artefact}

The 'maintenance optimisation artefact' emerged as the most frequently identified artefact. Several manufacturers highlighted how critical the optimisation of their product maintenance efforts is for the effective delivery of the product uptime value propositions. Offering product uptime implies that the manufacturer takes on the ongoing product maintenance responsibility, which they seek to optimise to reduce cost and unplanned downtime. The representatives explained how the IoT enables the manufacturers to move from a generic to a specific product maintenance schedule, based on the insights of the individual product's usage and circumstances. More specifically, they explained how the IoT helps to (i) understand the individual product's risk of failure, and (ii) identify the optimal time for maintenance and planned downtime (i.e. predictive maintenance), taking into account risks, costs, and both the customer and manufacturer's processes.

Further analysis specified the technology, information and social subsystems that, through their interaction, create this critical maintenance optimisation. The representatives' descriptions highlighted several technologies that contribute to the manufacturers' maintenance optimisation, by capturing real-time insights of the product use and the state of its individual components through product-based sensors and connectivity. In addition, the descriptions explained how external data sources (outside the product) provide an even more refined understanding of the context in which the product is used, as well as maintenance optimisation requirements. For example, for case [9], capturing data on the quality of the incoming steam and water utilities helps to create a more accurate recognition of their product's maintenance needs.

[Either] they have to do something about the utilities coming to the machine or we know that we have to replace the parts more often than we did before. [9]

The representatives' descriptions also highlighted the important roles diagnostic and analytical systems have in the processing of the captured data. However, the analysis of the maintenance optimisation scenarios also identified several information subsystems (i.e. thresholds, algorithms and accumulated product histories) as critical for manufacturers to effectively utilise the captured product-use data for maintenance optimisation. Representatives described how clear thresholds (alone or in combination) are essential to interpret - or 'fingerprint' - the product-use data, determine its failure risk, and identify the individual maintenance requirements: 
We can fingerprint [...] the normal operating parameters of the machine and, then, there's a number of things that we can track, analyse and calculate that will give us either a relatively short-term prediction of failure [or] a longer-term prediction of failure. [6]

The accumulated product history and algorithms were described as critical for the further processing of the captured product-use data and maintenance schedule optimisation:

We can get the status of most of the components ... and this combined with data histories which we have for the customer about the [products]. So, we have some good transparency to see what will happen with the [product], depending on transaction cycles and with the right algorithm ... recognise to which [product] an engineer, in the near future, must go. [12]

In addition to the technology and information subsystems, the analysis further identified social subsystems in the form of a mutually trusting manufacturer-customer relationship as a critical enabler of maintenance optimisation. A trusting manufacturer-customer relationship is critical to overcome the customer's concerns and facilitate the manufacturers' access to the critical product-use data:

These customers ... are just very, very paranoid about the potential for leakage of any information that would allow their competitors to understand how they're doing what they're doing. [6]

In addition to access considerations, representatives highlighted how tight collaboration in the early stages facilitate the manufacturers' ability to further interpret the data. The willingness to collaborate is illustrated by the representative description, in case [6], of the particular challenge of calibrating the algorithms to optimise data analysis and subsequent maintenance efforts:

It's hard to be confident that you've absolutely recognised a pre-failure signal without letting some machines fail. So, there's always a little bit of tension when you kind of go in and say, hey, we can prove that we can tell when one of your machines is going to fail, but we're going to have to let a few fail first. [6]

Customer-site product tests are required to effectively interpret the data within the context of the customers' processes.

While the IoT technology provides manufacturers with the technical tool to access the critical product-use data, the trusting social relationship facilitates the access permission, and the thresholds and algorithms help derive the necessary insights that can optimise product maintenance. The maintenance optimisation artefact is created by the interaction between technology, information and social subsystems. 


\begin{tabular}{|c|c|c|c|c|c|}
\hline \multicolumn{3}{|c|}{ The IoT-enabled IS artefact } & \multirow{2}{*}{\multicolumn{2}{|c|}{$\begin{array}{l}\text { Subsystems and their enabling role } \\
\text { TS=Technology subsystem, IS= Information subsystem, SS= Social subsystem }\end{array}$}} & \multirow[b]{2}{*}{ Cases } \\
\hline & $\begin{array}{c}\text { IS artefact } \\
\text { (artefact's core utility) }\end{array}$ & $\begin{array}{l}\text { Contribution to advanced } \\
\text { service value proposition }\end{array}$ & & & \\
\hline \multirow{12}{*}{ 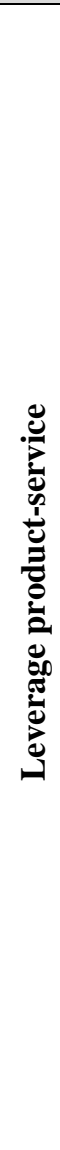 } & \multirow{3}{*}{$\begin{array}{l}\text { Maintenance optimisation } \\
\text { artefact } \\
\text { (creates understanding of the } \\
\text { individual product's risk of } \\
\text { failure and optimal time for } \\
\text { maintenance and planned } \\
\text { downtime) }\end{array}$} & \multirow{3}{*}{$\begin{array}{l}\text { Contributes to product uptime } \\
\text { value proposition by } \\
\text { - minimizing unplanned } \\
\text { downtime } \\
\text { - reducing maintenance costs }\end{array}$} & TS & $\begin{array}{l}\text { IoT technology (sensor, connectivity) to capture product use and context } \\
\text { data } \\
\text { Diagnostic \& analytic systems to process product-use data }\end{array}$ & \multirow[t]{3}{*}{$\begin{array}{l}{[3],[4],[5],} \\
{[6],[9],[10],} \\
{[11],[12],[13]}\end{array}$} \\
\hline & & & IS & $\begin{array}{l}\text { Thresholds and product history to determine maintenance requirements } \\
\text { Algorithms to determine the optimal maintenance schedule }\end{array}$ & \\
\hline & & & SS & $\begin{array}{l}\text { Mutually trusting relationship to obtain real-time product-use data access } \\
\text { Opportunity for testing and calibrating product behaviour within customer } \\
\text { process }\end{array}$ & \\
\hline & \multirow{3}{*}{$\begin{array}{l}\text { Repair efficiency artefact } \\
\text { (creates understanding of the } \\
\text { product failure's root cause, } \\
\text { remote repair opportunities } \\
\text { and the expertise and spare- } \\
\text { parts required for repair) }\end{array}$} & \multirow{3}{*}{$\begin{array}{l}\text { Contributes to product uptime } \\
\text { value proposition by } \\
\text { - optimizing repair preparation } \\
\text { and minimize risk of return visit } \\
\text { - increasing speed of repair } \\
\text { - reducing cost of repair }\end{array}$} & TS & $\begin{array}{l}\text { IoT technology and diagnostic analytic systems to capture and process } \\
\text { product-use data } \\
\text { Shared screen and augmented reality technology to facilitate interactions }\end{array}$ & \multirow[t]{3}{*}{$\begin{array}{l}{[2],[3], \quad[4],} \\
{[5], \quad[6], \quad[7],} \\
{[9],[13],[14],}\end{array}$} \\
\hline & & & IS & $\begin{array}{l}\text { Thresholds, error codes, product history to determine root causes of product } \\
\text { failure }\end{array}$ & \\
\hline & & & SS & $\begin{array}{l}\text { Trusted relationship with customer to permit monitoring product-use } \\
\text { Direct interaction with customer based on root cause analysis results }\end{array}$ & \\
\hline & \multirow{3}{*}{$\begin{array}{l}\text { Consumables/wear parts } \\
\text { replenishment artefact } \\
\text { (creates understanding of the } \\
\text { customer's real-time } \\
\text { replenishment needs and } \\
\text { specifications of the product } \\
\text { requiring replenishment) }\end{array}$} & \multirow{3}{*}{$\begin{array}{l}\text { Contributes to continuous } \\
\text { consumables/wear part } \\
\text { availability value proposition by } \\
\text { - ensuring availability and } \\
\text { responsiveness } \\
\text { - reducing warehousing costs }\end{array}$} & TS & $\begin{array}{l}\text { IoT technology and analytic system to capture extend of product use and } \\
\text { consumable levels }\end{array}$ & \multirow{3}{*}{$\begin{array}{l}{[1],[2], \quad[5],} \\
{[7],[9],[13],} \\
{[14]}\end{array}$} \\
\hline & & & IS & $\begin{array}{l}\text { Thresholds, algorithms to identify optimal time for replenishment or } \\
\text { replacement }\end{array}$ & \\
\hline & & & SS & Trusted relationship with customer to permit monitoring product-use & \\
\hline & \multirow{3}{*}{$\begin{array}{l}\text { Fleet management } \\
\text { administration artefact } \\
\text { (creates records of product- } \\
\text { use and interventions carried } \\
\text { out on the product) }\end{array}$} & \multirow{3}{*}{$\begin{array}{l}\text { Contributes to administrative } \\
\text { burden reduction value } \\
\text { proposition by } \\
\text { - optimising the documentation } \\
\text { requirements }\end{array}$} & TS & $\begin{array}{l}\text { IoT technology and repository to capture extend of product use and } \\
\text { interventions } \\
\text { Portal to display fleet management documentation }\end{array}$ & \multirow[t]{3}{*}{ [1], [3] } \\
\hline & & & IS & Thresholds to show compliance with standards & \\
\hline & & & SS & $\begin{array}{l}\text { Trusted relationship with customers to permit monitoring product-use and } \\
\text { create confidence in manufacturers documentation/compliance accuracy }\end{array}$ & \\
\hline
\end{tabular}




\begin{tabular}{|c|c|c|c|c|c|}
\hline \multirow{6}{*}{ 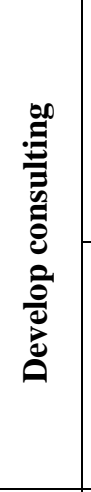 } & \multirow{3}{*}{$\begin{array}{l}\text { Operational context advise } \\
\text { artefact } \\
\text { (creates understanding of the } \\
\text { customer's product-use } \\
\text { context efficiency and } \\
\text { utilization rates) }\end{array}$} & \multirow{3}{*}{$\begin{array}{l}\text { Contributes to optimisation } \\
\text { services value proposition by } \\
\text { - effectively and efficiently } \\
\text { advising on optimisation } \\
\text { potential }\end{array}$} & TS & $\begin{array}{l}\text { IoT technology and diagnostic analytic system to capture and process } \\
\text { product-use and external sensor data }\end{array}$ & \multirow{3}{*}{$\begin{array}{l}{[1],[2],[3],} \\
{[9],[10],[12],} \\
{[14],[15]}\end{array}$} \\
\hline & & & IS & Benchmark database and algorithms to determine optimisation potential & \\
\hline & & & SS & $\begin{array}{l}\text { Direct interaction with customer based on analytics to discuss the } \\
\text { optimisation potential }\end{array}$ & \\
\hline & \multirow{3}{*}{$\begin{array}{l}\text { Customer self-repair } \\
\text { assistance artefact } \\
\text { (creates the function to reuse } \\
\text { their expertise and automate } \\
\text { its application) }\end{array}$} & \multirow{3}{*}{$\begin{array}{l}\text { Contributes to product usage } \\
\text { support value proposition by } \\
\text { - effectively and efficiently } \\
\text { make its own expertise available } \\
\text { for external usage }\end{array}$} & TS & $\begin{array}{l}\text { IoT technology and diagnostic analytic system to capture and process } \\
\text { product-use data } \\
\text { Automation and content delivery platforms to provide targeted content }\end{array}$ & \multirow[t]{3}{*}{$\begin{array}{l}{[3],[9],[10],} \\
{[11],[14]}\end{array}$} \\
\hline & & & IS & $\begin{array}{l}\text { Algorithms to identify maintenance and repair requirements } \\
\text { Maintenance and repair manuals and videos }\end{array}$ & \\
\hline & & & SS & Helpdesk interactions to guide self-repairs & \\
\hline \multirow{6}{*}{ 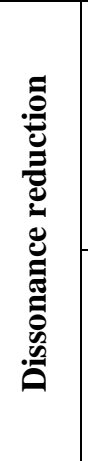 } & \multirow{3}{*}{$\begin{array}{l}\text { Service contribution } \\
\text { artefact } \\
\text { (creates a shared } \\
\text { understanding of the } \\
\text { provided service } \\
\text { contributions) }\end{array}$} & \multirow{3}{*}{$\begin{array}{l}\text { Contributes to product uptime } \\
\text { value proposition by } \\
\text { - effectively establishing } \\
\text { objective insights }\end{array}$} & TS & IoT technology to evidence product performance & \multirow{3}{*}{$\begin{array}{l}{[2],[4],[6],} \\
{[9],[10],[12],} \\
{[14],}\end{array}$} \\
\hline & & & IS & Historical data to display trends and improvements created & \\
\hline & & & SS & Direct interaction with customers to jointly interpret the data & \\
\hline & \multirow{3}{*}{$\begin{array}{l}\text { Operational misuse alert } \\
\text { artefact } \\
\text { (creates the function to } \\
\text { monitor product-usage } \\
\text { within agreed parameters) }\end{array}$} & \multirow{3}{*}{$\begin{array}{l}\text { Contributes to product } \\
\text { performance value proposition } \\
\text { by } \\
\text { - objectively demonstrating and } \\
\text { mitigating misuse }\end{array}$} & TS & IoT technology to evidence product misuse & \multirow[t]{3}{*}{ [1], [4], [9] } \\
\hline & & & IS & Thresholds to alert product misuse & \\
\hline & & & SS & Direct interaction to discuss misuse incidents and mitigation strategies & \\
\hline \multirow{3}{*}{ 总 } & \multirow{3}{*}{$\begin{array}{l}\text { Learning and } \\
\text { understanding artefact } \\
\text { (creates the function to } \\
\text { develop and share insights } \\
\text { on advanced service } \\
\text { business principles) }\end{array}$} & \multirow{3}{*}{$\begin{array}{l}\text { Contributes to optimisation } \\
\text { services value proposition by } \\
\text { - developing wider insights } \\
\text { across the organisation }\end{array}$} & TS & $\begin{array}{l}\text { IoT technology to capture product use data } \\
\text { Modelling and simulation systems to establish insights }\end{array}$ & \multirow[t]{3}{*}{$\begin{array}{l}{[1],[3],[5],} \\
{[8],[13],[15]}\end{array}$} \\
\hline & & & IS & Historical data as basis for scenario modelling & \\
\hline & & & SS & Direct staff interaction and knowledge sharing & \\
\hline
\end{tabular}




\section{Repair efficiency artefact}

The 'repair efficiency artefact', which provides manufacturers with the ability to capably respond to product failures, emerged as another critical IS artefact from the analysis of the IoT contribution scenarios. It was shown to directly contribute to the manufacturers' ability to offer product uptime value proposition. In detail, the representatives described how, upon product-failure, the IoT helps the manufacturers to (1) determine the failure's root cause, (2) assess remote repair opportunities ${ }^{2}$, and, if required, (3) despatch engineers with the required expertise, spare-parts and tools to minimise the risk of costly return visits.

The representatives' descriptions of the interacting subsystems that underlie the repair efficiency artefact highlighted the enabling roles of the IoT technology (sensors and connectivity) and the analytical systems, as well as the shared screen technology and augmented reality devices that support interactions with the customers' local technicians to facilitate remote repair efforts.

Being able to dial in and connect to the machine and share the same screen as the [operator] or the local support engineer can see on the device - that's become quite an efficiency saving for us. [3]

The analysis further established how the information subsystems, in the form of errorcodes, thresholds and product-history, help the manufacturers to analyse the product-use data and determine the root cause of product failure. In addition to representatives highlighting how trusting relationships (social subsystems) facilitate important data access, the analysis identified how, in turn, the data access facilitates critical manufacturer-customer interactions in repair scenarios, as explained here:

We can actually get to the fault first; we have a decision-making process that [determines] the action we need to take. We call up the customer and let them know, then we're cutting out a whole lot of communication with the customer and telling them there and then, you know, what the problem is and what the solution is. [7]

Thus, the manufacturers' ability to respond successfully to product failures is based on the contribution of different subsystems and their complex interactions.

\section{Consumable/wear part replacement artefact}

Another widely encountered IoT-based IS artefact identified was the 'consumable/wear part replacement artefact', which provides manufacturers with the ability to effectively offer replacement services as a viable offer. The advanced service value propositions of several manufacturers include the replacement of wear parts, either as part of a wider offering (e.g. product uptime) or as a separate value proposition (e.g. continuous consumables/wear part availability). Case [5], for example, considers the provision of consumables as an essential part of its revenue model:

Most of the hardware in the ... industry remains on the balance sheet of the provider, like ourselves. We sell reagent to customers and, in most cases, there is a contract that defines minimum reagent consumption for a year and that pays for the hardware as well. [5]

When taking on the responsibility for the availability of the customers' consumable/wearparts, it becomes critical for manufacturers to (i) predict the consumable/wear-part needs

\footnotetext{
${ }^{2}$ Remote repair opportunities dramatically reduce repair costs and, in case [4], 80\% of repairs are already carried out remotely.
} 
to ensure availability; (ii) minimise the warehousing cost and part obsolescence in order to remain efficient; and (iii) know the exact specifications of the product that requires replacement. In case [13], a machine manufacturer describes the importance of meeting these requirements before being able to offer replacement services:

We can record all the components at the customer's site [...] and we can set up a scenario to replace [the component]. So, we can build up each replacement component so we know about a delivery time, we know about manufacturing time and only then can we give the customer these kinds of contracts. [13]

The analysis further explored the underlying subsystems and the interactions that create the consumable/wear part replacement artefact. As above, the artefact relies on IoT technology (sensors and connectivity), analytics software and thresholds to create, retrieve and process the product-use data in order to determine demand.

We know exactly how many [consumables] they use, because we know how many programmes they run of a certain type. So, we take care of the stock management for them, just by sending it out automatically, which means that they save money because they don't have as much working capital on their shelves. And we tie them closer because, now, they are buying our products and not the competitors' products. [9]

More complex wear-part replacement models require predictive algorithms (information subsystems) to understand and predict the state of the individual part that is to be replaced.

The social subsystem, a trusting manufacturer-customer relationship, provides the basis for the manufacturers' access to the sensitive product-use data required (e.g. production cycles), and also affords customers the confidence to abandon their own warehousing of essential consumables and rely on their manufacturers' capabilities.

\section{Fleet management administration artefact}

The analysis also identified the 'fleet management administration artefact' as a core IS artefact, providing manufacturers with the ability to reduce customers' administrative burden associated with the use of the product. Hence, the generation of administrative efficiency and innovation determines the viability of turning this ability into a value proposition. To forge administrative efficiency, it is critical that manufacturers are able to effectively (i) monitor the product use, and (ii) monitor the extent of interventions.

The analysis explored the subsystems and interactions that enable the manufacturers' fleet management administration artefact. Comments highlighted the role of technology subsystems in the form of IOT technology (sensors and connectivity) and web-interfaces in order to retrieve and process the product-use data and display interventions ready for inspection.

They also highlighted the role of thresholds (an information subsystem) to interpret the product-use data and show compliance with standards (e.g. emissions) and the role of contracts and relationships (a social subsystem) to obtain access. The representatives reported that data which revealed insights pertaining to customers' production processes was considered to be very sensitive.

\section{Develop consulting function}

Among the identified IoT-enabled IS artefacts, two were found to provide utilities that support the manufacturers in their efforts to offer consulting services to customers. 


\section{Operational context advice artefact}

The analysis identified the 'operational context advice artefact' as an IS artefact that provides manufacturers with the ability to offer customers well-grounded advice on the use of the products within a specific context, as required when offering 'optimisation services'. The analysis identified how manufacturers use the IoT to engage in: (i) context interference diagnostics (to establish how the customers' context affects its product use); (ii) product choice optimisation (to establish the product type best suited for customers' use patterns); (iii) product use efficiency assessment (to establish the context-based efficiency and utilisation rates); and (iv) process output analysis (to establish the customers' overall process performance). The viability of the 'optimisation services' value propositions depends on the manufacturers' ability to apply their expertise to the product and context insights.

The analysis specified the interacting technology, information and social subsystems that, together, create the utility that manufacturers require to provide this kind of advice. In addition to the product-based IoT technology and analytical systems required to retrieve and process the product-use data, the representatives highlighted the need for external sensors to capture critical insights regarding the context. They also discussed their use of web-based portals to effectively present their customers with critical product, context and process insights.

They can see this report per equipment. So, they can see [...] the amount of product gone through, or the utilisation of the equipment, or failures happening, or whatever they want to see is provided over there. [10]

Further, the roles of benchmarks and algorithms (information subsystems) were highlighted to identify the product-context fit and determine its optimisation potential.

Focusing on social subsystems, representatives not only emphasised mutual trust as a critical enabler for data access (context data in particular), but also stressed how the data enables the development of trust:

[The data helps me to prepare] the phone calls that I make to [customer] every Monday morning, talking about his vehicles, why they are doing seven and half to the gallon and not eight and a half to the gallon. That is cementing the relationship all the time. [The customer] knows that I am thinking about his fleet. [1]

The IoT technology is certainly a critical enabler for manufacturers to gain access to product-use data. In addition, however, in order for manufacturers to be able to offer customers well-grounded advice on the use of their products, interactions between technology, information and social subsystems are required.

\section{Customer self-repair assistance artefact}

The analysis also identified the 'customer repair assistance artefact' as an IS artefact that helps manufacturers to make their product maintenance and repair expertise available to customers who choose to carry out their own repairs, as in the case of the 'product usage support' propositions. Providing maintenance and repair expertise directly to customers represents an opportunity for manufacturers to reuse their knowledge and extend (and monetize) it. However, it is necessary that manufacturers are able to deliver this value proposition efficiently and effectively at scale (including to remotely located customers).

The analysis of the subsystems creating this utility not only identified the core IoT technology (sensors and connectivity) for capturing product-use data, but also the important roles of automation and content delivery platforms (e.g. portals) in ensuring the scalability of the service provision. However, the core contribution these platforms can 
provide is dependent on the algorithms that help to identify optimised maintenance requirements, the root causes of product failures, and their ability to direct the customers to the required maintenance and repair manuals and videos (information subsystems). Despite the focus on automation, the representatives also highlighted the importance of additional helpdesk interactions to guide customers who have chosen to carry out repairs on their products.

While the IoT technology extends manufacturers' opportunities for offering their expertise as separate consulting services, interactions with other technology, information and social subsystems are required to be able to effect concrete utilities.

\section{Dissonance reduction function}

The analysis further identified two IoT-enabled IS artefacts that help manufacturers to mediate relationships with their customers.

\section{Service contribution artefact}

The analysis identified how the 'service contribution artefact' supports the manufacturercustomer relationship by bringing about a shared understanding of the advanced service value that has been created. For example, the successful delivery of 'product uptime' ultimately implies that the product performs as expected. However, the manufacturers' efforts required to achieve this outcome may not be clearly understood, and this can create tensions around the created service value and justifiability of its cost, as indicated by the case [6] representative:

So, one of our difficulties is actually ... putting a value to these [services]. We have a good understanding that time is money and lost production [due to our product] failing during the middle of a process, are all things which have a cost, but it's quite difficult to pin an actual number on that. [6]

Several IoT contribution scenarios that have been analysed illustrate how the IoT technology helps manufacturers to develop a shared understanding of the service contribution they have created; the representatives' descriptions explain the subsystems that facilitate this shared understanding. These include technology subsystems, in terms of IoT sensors and connectivity to show evidence of product performance, and also historical data (information subsystems) to be able to display trends and improvements that have been built.

We have the knowledge of the equipment and we try to improve the process and show the customer, okay, your process line is now running at a certain performance and we enhance that by giving you either more uptime, or better liability, or a better performance, a better output of your process line. [10]

Of particular interest is the manufacturers' emphasis on the importance of direct interaction with the customer, in order to utilise performance data and create a shared understanding of the service value.

[Our reports help us to] have a dialogue with the customer. Before it was 'it never works or it always works', there wasn't any kind of granularity between them. So, a customer could say, 'It never works', and we would say, 'Well it is working now.' ... So, now, just based on the reporting of the performance statistics, there is shared clarity on the amount of errors. [9] 
By helping manufacturers bring about this shared understanding of the advanced service value, the service contribution artefact helps to mediate the manufacturer-customer relationship.

\section{Operational misuse identification artefact}

The analysis of the IoT contribution scenarios also identified the 'operational misuse identification artefact' as a critical IS artefact that helps manufacturers avert manufacturer-customer dissonance linked to product misuse. Ensuring that the product is being used appropriately was highlighted as one of the core challenges when offering advanced service value propositions, where manufacturers retain responsibility for product performance (i.e. 'product uptime'). Product misuse threatens the manufacturers' uptime guarantees, and may create dissonance when seeking to assess the product's performance. By helping manufacturers to (i) objectively demonstrate misuse, and (ii) mitigate misuse, the 'operational misuse identification artefact' provides a utility that helps manufacturers to avert this dissonance.

The IoT technology is critical for the creation of these utilities as it enables the productuse data, which can then be analysed to record evidence of misuse. However, the analysis also identified how the artefact's core utilities (i.e. to demonstrate and mitigate misuse) requires direct manufacturer-customer interactions involving discussions on possible training to minimise future misuse. The analysis of the product-use data provides the basis for these interactions. While the technology and information subsystems provide the empirical basis for identifying service contributions and product misuse, social interactions are critical in order to effectively avert dissonance in the manufacturercustomer relationship.

\section{Knowledge creation function}

One IoT-enabled IS artefact was identified that helps manufacturers develop and manage the critical expertise required for advanced service development and delivery.

\section{Learning and understanding}

The 'learning and understanding artefact' emerged as an important IS artefact to help manufacturers with the creation and internal distribution of advanced service insights. For manufacturers, advanced service value propositions such as 'optimisation services' represent new organisational ventures for which they are still lacking a complete understanding. Manufacturers need to learn specific advanced service principles, and this is illustrated by the case [1] representative's description of the customer's risk profiles when considering product uptime service offers:

We know exactly how [the customer] operates its trucks because [the customer] has a B class or an A class fleet; therefore, the repair and maintenance side of this should be less expensive ... We're going to give a price that's less expensive because we know how [the customer] operates its trucks within the parameters, right, so, therefore, we're quite prepared to be less expensive for our services. [1]

In order to provide these value propositions effectively, it is critical for manufacturers to systematically develop insights in relation to these new advanced service business principles, and share these across the organisation. The analysis showed how the subsystem interactions enable the creation and internal distribution of these advanced service insights. The representative's comments specifically point to the role of modelling and simulation tools in establishing those well-grounded insights. These, then, become a resource to facilitate training: 
We got some of the more experienced engineers to find maybe 150 different alarm situations that we think that they would want to know about and that started to enable new engineers and the less experienced ones to start understanding what's happening with their customer problems and start seeing things before the customers reported them. [3]

The data, therefore, provides support for staff interactions and knowledge-sharing for manufacturers, which are fundamental for the gathering and sharing of insights.

\section{Discussion and conclusions}

This study sets out to investigate how the IoT contributes to the advanced services that manufacturers are offering to their customers. While the IoT is widely recognised as a technology enabler for advanced services (Coreynen, Matthyssens, \& Van Bockhaven, 2016), there are still gaps in our understanding of the range of activities and resources that facilitate the IoT's contributions and how they should be managed. The conceptualisation of the 'IoT-enabled IS artefact' establishes a socio-technical interpretation of the IoT and its contribution: it shifts the focus from the technology to the interaction between the technology and its social and organisational context as a source of the critical utility.

In order to account for the diverse advanced services that manufacturers offer, the study focused on the individual value propositions as the unit of analysis to identify the IoT contributions. The case data offered insights into a diversity of advanced service value propositions and the range of specific utilities the IoT provides to them. The delivery of the 'product-uptime' proposition, for example, was found to rely on the 'repair efficiency', 'maintenance optimization', 'wear part replacement', 'dissonance reduction' and 'operational misuse identification' utilities that the IoT provides to the manufacturer.

By identifying how the diverse value propositions are supported by such a wide range of utilities, the findings show the ways in which the manufacturers' advanced services are dependent on the IoT and highlight the complexity that underlies the IoT contributions: while a value proposition may draw on a range of IoT-based utilities, an individual utility may support a diversity of value propositions. This finding extends prior research that focuses on an exclusive link between the IoT and a dedicated value proposition March and Scudder (2019); Spring and Araujo (2017). Designing an IoT technology that supports diverse and emerging value propositions and stakeholders requires negotiation skills that go beyond the technical IoT capabilities commonly discussed (Ancarani, Di Mauro, Legenvre, \& Cardella, 2019).

The findings also show how such IoT-based utilities are created. In none of the identified scenarios is it the case that the IoT technology directly creates the utility that supports the advanced service value proposition. Instead, the findings show how the IoT technology is embedded in a system comprising different social and information subsystems which create these utilities through their interaction. Within this system, the IoT technology enables other subsystems (e.g. providing product use data for further analysis), but also draws on them (e.g. facilitating data access through trusted customer relationships). This differentiated socio-technical view of the IoT technology's role in the advanced services context adds important context to the prior servitization research that limits the investigations into the IoT technology itself (e.g. Cortez \& Johnston, 2017; March \& Scudder, 2019; Spring \& Araujo, 2017). By providing comprehensive illustrations of the different mechanisms, the present findings 'unpack' how the critical utilities are derived from the IoT technology. 
Of particular interest are the findings concerning the multifaceted role the manufacturercustomer-relationship (in the form of social subsystem) has in the creation of the IoT contributions. On the one hand, the findings show how dependent the IoT-based utilities are on this relationship, as they enable the manufacturer to access the critical product-use data. Although the servitization literature emphasises the importance of interorganisational relationships for advanced services in general (Story et al., 2017), their importance for the realisation of the IoT opportunities are not yet widely considered. On the other hand, the findings also show how the IoT technology enables the manufacturercustomer-relationship, by presenting a clear evidence base that minimizes dissonance. This finding suggests that IoT technology can make these relationships more advantageous as they are based on objective data and an in-depth understanding of service-performance. This means that adoption of IoT technology will not necessarily prioritise operational efficiency gains over the customer relationship (Tabrizi, Lam, Girard, \& Irvin, 2019).

Of additional interest is the far-reaching role that data plays in the creation of the IoT contributions. The analysis not only identified the importance of the product-use data that the IoT-based connectivity continuously provides to the manufacturer; it also identified how critical the established information subsystems (e.g. benchmarks, algorithms) are for the interpretation of the product-use data and therefore for the creation of the IoT-based utility. Yet these information subsystems are often derived from product-use data that has previously been retrieved and processed with the help of the IoT technology. Hence, although the servitization research highlights the ability of the IoT to facilitate the monitoring of the products in use (e.g. Suppatvech et al., 2019), it also needs to take into account the importance of those data resources that need to be developed in order to support the creation of the IoT contributions.

\subsection{Contributions to servitization research}

Based on the findings, the study makes two important contributions to servitization and operations management research. First, the study introduces a socio-technical systems perspective (Land \& Hirschheim, 1983) into the understanding of the IoT contribution. Such a perspective provides the servitization literature with an expanded viewpoint on the creation of the IoT contributions, by drawing attention to the context in which these contribution are created.

Second, the development of the 'IoT-enabled IS artefact' provides a theory-based framework that enables the systematic investigation of the IoT contribution in an advanced services context. Its focus on the specific utility that the IoT creates provides an opportunity to differentiate between the range of contributions the IoT creates and to thereby develop the detailed understanding of the IoT contribution that is required to ensure impactful research and support insightful management initiatives (Hong et al., 2014).

\subsection{Contributions to servitization practice}

The study also raises important implications for managers exploring the opportunities that the IoT provides for advanced services. The findings clearly show that the IoT, in an advanced services context, should not be managed as an isolated technical project. As the contributions of the IoT technology are enabled by a variety of technical, information and social resources and activities it is critical to align their management to effectively capitalize on the IoT technology investments.

The findings also emphasise the importance of prioritizing the advanced services value propositions to guide the IoT developments. At times, manufacturers engage with the 
development of their IoT solutions and subsequently explore advanced services offerings as an opportunity to monetize their IoT investments (Sinclair, 2017). The range of diverse resources and activities that is required to support a value proposition makes their retrospective development and integration difficult.

In addition, as several of the essential sub-systems that have been identified (e.g. benchmarks, trust) require lengthy development, managers should already now formulate those value propositions they want to offer in the future in order to ensure the necessary subsystems are in place when required. The development of the critical data resources and relationships may take a considerable amount of time, which may even exceed the development of the IoT technology itself.

\subsection{Limitations}

It is important to also note the study's limitations. First, the study only captured scenarios from large, multinational manufacturers, which needs to be taken into consideration when seeking to transfer the findings to an SME context. This choice of case organisations may partly determine the range of advanced services value propositions and IoT contributions that can be identified. Second, the study identified a diversity of value propositions and artefacts from the case data, which allowed for an illustration of the artefact framework and a theorisation of the roles that the subsystems play. These findings should not be considered exhaustive, and other organisations and advanced service scenarios may reveal further contributions. Third, the choice of method also has inherent limitations. Although the study relied on a diversity of interviewees to provide a balanced and rich perspective, more interviews could have further expanded the findings. Fourth, while the data was analysed in a team context, and significant time was spent in consolidating the interpretations of the data, other researchers might have drawn additional conclusions.

\subsection{Opportunities for future research}

Despite these limitations, the study creates concrete opportunities for future research. It provides an important opportunity for future research to develop a network perspective on the IoT contributions and their enabling subsystems (Jagdev \& Thoben, 2001; Möller, 2013). A network perspective would explore how manufacturers utilise the subsystems of third parties to create the IoT contribution. The literature already describes cases where manufacturers outsource aspects of the information subsystem (i.e. data hosting and analysis) and the social subsystem (i.e. outsourcing support or sales function) (Story et al., 2017). Future research should investigate how these subsystems can be systematically developed and integrated across a network to create the IoT-enabled IS artefacts manufacturers require to develop and deliver their advanced service value propositions.

Future research should explore how the continuous development efforts of the subsystems can be aligned with the organisational transformation processes that manufacturers undergo to be able to fully capitalize on their advanced service offerings (Baines et al., 2020). Research should investigate how the dynamics of the organisational transformation and exploration can be aligned with the long-term strategic development that the IoT-related activities and resources require.

This study provides important insights explaining how the IoT contributes to advanced services, and offers a variety of opportunities for future research to investigate the intersection between these two domains. The IoT provides substantial opportunities for the development and delivery of advanced services, but also creates a complex web of socio-technical dependencies that need to be understood and managed to effectively realize its contributions. 


\section{References}

Ancarani, A., Di Mauro, C., Legenvre, H., \& Cardella, M. S. (2019). Internet of things adoption: a typology of projects. International Journal of Operations \& Production Management, xx(xx), xx-xx.

Ardolino, M., Rapaccini, M., Saccani, N., Gaiardelli, P., Crespi, G., \& Ruggeri, C. (2018). The role of digital technologies for the service transformation of industrial companies. International Journal of Production Research, 56(6), 2116-2132.

Association of Business Schools. (2018). Academic journal guide. Retrieved from http://charteredabs.org/academic-journal-guide-2018/, (accessed 27 Jan, 2020).

Avgerou, C. (2001). The significance of context in information systems and organizational change. Information Systems Journal, 11(1), 43-63.

Baines, T., Bigdeli, A. Z., Sousa, R., \& Schroeder, A. (2020). Framing the servitization transformation process: A model to understand and facilitate the servitization journey. International Journal of Production Economics, 221, 107463.

Baines, T., \& Lightfoot, H. (2013). Made to serve: How manufacturers can compete through servitization and product service systems. Chichester, UK: John Wiley \& Sons.

Baines, T., \& Lightfoot, H. W. (2014). Servitization of the manufacturing firm. International Journal of Operations \& Production Management, 34 (1), 2-35.

Beier, G., Ullrich, A., Niehoff, S., Reißig, M., \& Habich, M. (2020). Industry 4.0: How it is defined from a sociotechnical perspective and how much sustainability it includes-A literature review. Journal of Cleaner Production, 120856.

Boehmer, J. H., Shukla, M., Kapletia, D., \& Tiwari, M. K. (2020). The impact of the Internet of Things (IoT) on servitization: an exploration of changing supply relationships. Production Planning \& Control, 31(2-3), 203-219.

Braun, V., \& Clarke, V. (2006). Using thematic analysis in psychology. Qualitative research in psychology, 3(2), 77-101.

Cagliano, R., Canterino, F., Longoni, A., \& Bartezzaghi, E. (2019). The interplay between smart manufacturing technologies and work organization. International Journal of Operations \& Production Management, 39(6/7/8), 913-934.

Chakkol, M., Karatzas, A., Johnson, M., \& Godsell, J. (2018). Building bridges: Boundary spanners in servitized supply chains. International Journal of Operations \& Production Management, 38(2), 579-604.

Cisco. (2017). Connected futures. Retrieved from https://t.co/0w4f5xqqCt, (accessed 25 Jan, 2020).

Coreynen, W., Matthyssens, P., \& Van Bockhaven, W. (2016). Boosting servitization through digitization: Pathways and dynamic resource configurations for manufacturers. Industrial Marketing Management, 60, 42-53.

Cortez, R. M., \& Johnston, W. J. (2017). The future of B2B marketing theory: A historical and prospective analysis. Industrial Marketing Management, 66, 90-102.

Dubé, L., \& Paré, G. (2003). Rigor in Information Systems Positivist Case Research. MIS Quarterly, 27(4), 597-635.

Economist Intelligence Unit. (2020). The internet of things: Applications for business. Retrieved from https://pages.eiu.com/rs/753-RIQ438/images/18062020_CTE\%20Report_Final.pdf, (accessed 22 February, 2020).

Edquist, H., Goodridge, P., \& Haskel, J. (2019). The Internet of Things and economic growth in a panel of countries. Economics of Innovation and New Technology, 122.

Eisenhardt, K. M. (1989). Building theories from case study research. The Academy of Management Review, 14(4), 532-550. 
Fischer, M., Heim, D., Hofmann, A., Janiesch, C., Klima, C., \& Winkelmann, A. (2020). A taxonomy and archetypes of smart services for smart living. Electronic Markets, 1-19.

Fliess, S., \& Lexutt, E. (2019). How to be successful with servitization-Guidelines for research and management. Industrial Marketing Management, 78, 58-75.

Frank, A. G., Mendes, G. H., Ayala, N. F., \& Ghezzi, A. (2019). Servitization and Industry 4.0 convergence in the digital transformation of product firms: A business model innovation perspective. Technological Forecasting and Social Change, 141, 341-351.

Gibbert, M., Ruigrok, W., \& Wicki, B. (2008). What passes as a rigorous case study? Strategic Management Journal, 29(13), 1465-1474.

Grubic, T., \& Jennions, I. (2018). Do outcome-based contracts exist? The investigation of power-by-the-hour and similar result-oriented cases. International Journal of Production Economics, 206, 209-219.

Guba, E. G., \& Lincoln, Y. S. (1994). Competing paradigms in qualitative research. In N. K. Denzin \& Y. S. Lincoln (Eds.), Handbook of Qualitative Research (pp. 105117). Thousand Oaks: SAGE Publications limited.

Handfield, R. (2019). Shifts in buyer-seller relationships: A retrospective on. Industrial Marketing Management, 83, 194-206.

Hasselblatt, M., Huikkola, T., Kohtamäki, M., \& Nickell, D. (2018). Modeling manufacturer's capabilities for the Internet of Things. Journal of Business \& Industrial Marketing, 33(6), 822-836.

Herterich, M. M., Uebernickel, F., \& Brenner, W. (2015). The impact of cyber-physical systems on industrial services in manufacturing. Procedia Cirp, 30, 323-328.

Hong, W., Chan, F. K., Thong, J. Y., Chasalow, L. C., \& Dhillon, G. (2014). A framework and guidelines for context-specific theorizing in information systems research. Information Systems Research, 25(1), 111-136.

Iivari, J. (2017). Information system artefact or information system application: That is the question. Information Systems Journal, 27(6), 753-774.

Jacobides, M. G., \& Winter, S. G. (2012). Capabilities: Structure, agency, and evolution. Organization Science, 23(5), 1365-1381.

Jagdev, H. S., \& Thoben, K.-D. (2001). Anatomy of enterprise collaborations. Production Planning \& Control, 12(5), 437-451.

Johnsen, T. E., Miemczyk, J., \& Howard, M. (2017). A systematic literature review of sustainable purchasing and supply research: Theoretical perspectives and opportunities for IMP-based research. Industrial Marketing Management, 61, 130-143.

Kamp, B., \& Parry, G. (2017). Servitization and advanced business services as levers for competitiveness. Industrial Marketing Management, 60, 11-16.

Kowalkowski, C., Gebauer, H., Kamp, B., \& Parry, G. (2017). Servitization and deservitization: Overview, concepts, and definitions. Industrial Marketing Management, 60, 4-10.

Krotov, V. (2017). The Internet of Things and new business opportunities. Business Horizons, 60(6), 831-841.

Kull, T. J., Ellis, S. C., \& Narasimhan, R. (2013). Reducing behavioral constraints to supplier integration: A socio-technical systems perspective. Journal of Supply Chain Management, 49(1), 64-86.

Land, F., \& Hirschheim, R. (1983). Participative systems design: Rationale, tools and techniques. Journal of Applied Systems Analysis, 10(10), 15-18. 
Lee, A. S., Thomas, M., \& Baskerville, R. L. (2015). Going back to basics in design science: From the information technology artifact to the information systems artifact. Information Systems Journal, 25(1), 5-21.

Löfberg, N., \& Åkesson, M. (2018). Creating a service platform-how to co-create value in a remote service context. Journal of Business \& Industrial Marketing, 33(6), 768-780.

Long, T. B., Blok, V., \& Coninx, I. (2016). Barriers to the adoption and diffusion of technological innovations for climate-smart agriculture in Europe: Evidence from the Netherlands, France, Switzerland and Italy. Journal of Cleaner Production, 112, 9-21.

Lowry, P. B., Dinev, T., \& Willison, R. (2017). Why security and privacy research lies at the centre of the information systems (IS) artefact: Proposing a bold research agenda. European Journal of Information Systems, 26(6), 546-563.

Luz Martín-Peña, M., Díaz-Garrido, E., \& Sánchez-López, J. M. (2018). The digitalization and servitization of manufacturing: A review on digital business models. Strategic Change, 27(2), 91-99.

March, S. T., \& Scudder, G. D. (2019). Predictive maintenance: strategic use of IT in manufacturing organizations. Information Systems Frontiers, 21, 327-341.

Matthyssens, P., \& Vandenbempt, K. (2008). Moving from basic offerings to value-added solutions: Strategies, barriers and alignment. Industrial Marketing Management, 37(3), 316-328.

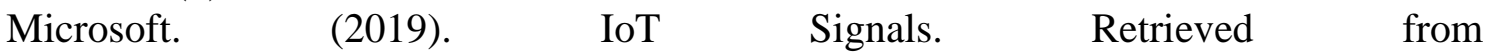
https://azure.microsoft.com/mediahandler/files/resourcefiles/iot-signals/IoTSignals-Microsoft-072019.pdf, (accessed 2020, 17 Jan).

Miles, M. B., \& Huberman, A. M. (1994). Qualitative data analysis: An expanded sourcebook. Thousand Oaks, California: SAGE publications, Inc.

Minerva, R., Biru, A., \& Rotondi, D. (2015). Towards a definition of the Internet of Things (IoT). IEEE Internet Initiative, 1, 1-86.

Möller, K. (2013). Theory map of business marketing: Relationships and networks perspectives. Industrial Marketing Management, 42(3), 324-335.

Musson, E., Baines, T., \& Ziaee Bigdeli, A. (2019). Advanced Service Business Models: Understanding their structure and basis for competitive advantage. The Advanced Services Group, Aston Business School, Birmingham, UK.

Opresnik, D., \& Taisch, M. (2015). The value of Big Data in servitization. International Journal of Production Economics, 165, 174-184.

Paiola, M., \& Gebauer, H. (2020). Internet of things technologies, digital servitization and business model innovation in BtoB manufacturing firms. Industrial Marketing Management, $x x(\mathrm{xx}), \mathrm{xx}-\mathrm{xx}$.

Paré, G., Trudel, M.-C., Jaana, M., \& Kitsiou, S. (2014). Synthesizing information systems knowledge: A typology of literature reviews. Information \& Management, 52(2), 183-199.

Raddats, C., Kowalkowski, C., Benedettini, O., Burton, J., \& Gebauer, H. (2019). Servitization: A contemporary thematic review of four major research streams. Industrial Marketing Management, 83, 207-223.

Raddats, C., Zolkiewski, J., Story, V. M., Burton, J., Baines, T., \& Ziaee Bigdeli, A. (2017). Interactively developed capabilities: Evidence from dyadic servitization relationships. International Journal of Operations \& Production Management, 37(3), 382-400. 
Raja, J. Z., Chakkol, M., Johnson, M., \& Beltagui, A. (2018). Organizing for servitization: Examining front-and back-end design configurations. International Journal of Operations \& Production Management, 38(1), 249-271.

Rymaszewska, A., Helo, P., \& Gunasekaran, A. (2017). IoT powered servitization of manufacturing-an exploratory case study. International Journal of Production Economics, 192, 92-105.

Schroeder, A., Ziaee Bigdeli, A., Galera Zarco, C., \& Baines, T. (2019). Capturing the benefits of industry 4.0: A business network perspective. Production Planning \& Control, 30(16), 1305-1321.

Sinclair, B. (2017). IoT Inc. New York: McGraw-Hill.

Sjödin, D. R., Parida, V., \& Kohtamäki, M. (2016). Capability configurations for advanced service offerings in manufacturing firms: Using fuzzy set qualitative comparative analysis. Journal of Business Research, 69(11), 5330-5335.

Sony, M., \& Naik, S. (2020). Industry 4.0 integration with socio-technical systems theory: A systematic review and proposed theoretical model. Technology in Society, 101248.

Sousa, R., \& da Silveira, G. J. (2017). Capability antecedents and performance outcomes of servitization: Differences between basic and advanced services. International Journal of Operations \& Production Management, 37(4), 444-467.

Spring, M., \& Araujo, L. (2017). Product biographies in servitization and the circular economy. Industrial Marketing Management, 60, 126-137.

Story, V. M., Raddats, C., Burton, J., Zolkiewski, J., \& Baines, T. (2017). Capabilities for advanced services: A multi-actor perspective. Industrial Marketing Management, 60, 54-68.

Suppatvech, C., Godsell, J., \& Day, S. (2019). The roles of internet of things technology in enabling servitized business models: A systematic literature review. Industrial Marketing Management, 82, 70-86.

Tabrizi, B., Lam, E., Girard, K., \& Irvin, V. (2019). Digital transformation is not about technology. Harvard Business Review. Retrieved from https://hbr.org/2020/05/digital-transformation-is-about-talent-not-technology,

Tao, F., \& Qi, Q. (2017). New IT driven service-oriented smart manufacturing: framework and characteristics. IEEE Transactions on Systems, Man, and Cybernetics: Systems, 49(1), 81-91.

Thomé, A. M. T., Scavarda, L. F., \& Scavarda, A. J. (2016). Conducting systematic literature review in operations management. Production Planning \& Control, 27(5), 408-420.

Turunen, T., Eloranta, V., \& Hakanen, E. (2018). Contemporary perspectives on the strategic role of information in internet of things-driven industrial services. Journal of Business \& Industrial Marketing, 33(6), 837-845.

Voss, C., Tsikriktsis, N., \& Frohlich, M. (2002). Case research in operations management. International Journal of Operations \& Production Management, 22(2), 195-219.

Yang, C., Lan, S., Shen, W., Huang, G. Q., Wang, X., \& Lin, T. (2017). Towards product customization and personalization in IoT-enabled cloud manufacturing. Cluster Computing, 20(2), 1717-1730.

Yin, R. K. (2005). The abridged version of case study research: Design and method. In E. Stern (Ed.), Evaluation Research Methods (pp. 3-34). Thousand Oaks, CA: Sage Publications.

Zancul, E., Takey, S. M., Barquet, A. P. B., Kuwabara, L. H., Cauchick Miguel, P. A., \& Rozenfeld, H. (2016). Business process support for IoT based product-service systems (PSS). Business Process Management Journal, 22(2), 305-323. 
Ziaee Bigdeli, A., Baines, T., Schroeder, A., Brown, S., Musson, E., Guang Shi, V., \& Calabrese, A. (2018). Measuring servitization progress and outcome: the case of 'advanced services'. Production Planning \& Control, 29(4), 315-332.

\section{Appendix}

\section{Review of the servitization literature}

The objective of the scoping review (Paré et al., 2014) was to examine the nature of the servitization research that investigates the IoT contributions to advanced services. In order to identify key publications on the topic, a search string combining IoT and servitization related keywords was used to query the Proquest and EBSCO databases. The search keywords included: ("Internet of things" OR "IoT") AND ("servitization" OR "servitisation" OR "advanced service"). To ensure that high-quality publications from the wider research domains were selected, the search scope was limited to publications from journals that the Academic Journal Guide 2018 (Association of Business Schools, 2018) has categorised as being of worldwide distinction ( $4 *$ rated journals), top in their field (4 rated journals), highly regarded (3 rated journals) or well regarded (2 rated journals). This journal list and rating rationale has been used to define the literature search scope in prior investigations (e.g. Johnsen, Miemczyk, \& Howard, 2017; Thomé, Scavarda, \& Scavarda, 2016; Ziaee Bigdeli et al., 2018).

The search process generated an initial corpus of 85 publications. The publications within the initial corpus were further examined individually to ensure that they yield relevant insights. To qualify for inclusion, publications had to provide a clear focus on the IoT and advanced services. Publications were rejected if they were limited to IoT functionalities in general or were focused on advanced services with minimal consideration of the IoT contribution. Only 14 publications met the required criteria and were used for further analysis. The analysis identified the advanced services aspects to which the IoT contributes, and the range of activities and resources that enable the IoT contributions. The analysis also considered the nature of the publication (i.e. empirical research, literature review, conceptual article). The result of the review is presented in Table 4.

Table 4. Result of scoping review

\begin{tabular}{|l|l|l|}
\hline \multicolumn{1}{|c|}{ Author } & \multicolumn{1}{|c|}{ IoT contributions } & $\begin{array}{l}\text { Activities and resources enabling } \\
\text { the IoT contribution }\end{array}$ \\
\hline Boehmer et al. $(2020)^{2}$ & Trusting relationship & IoT technology \\
\hline Cortez and Johnston $(2017)^{4}$ & Predictive maintenance & $\begin{array}{l}\text { IoT technology, variety of data } \\
\text { sources, }\end{array}$ \\
\hline Fischer et al. (2020) & Behavioural monitoring & $\begin{array}{l}\text { IoT technology, analytics } \\
\text { capabilities, trusting relationship }\end{array}$ \\
\hline Fliess and Lexutt $(2019)^{3}$ & $\begin{array}{l}\text { Creates stronger connectedness } \\
\text { across boundaries? }\end{array}$ & IoT technology \\
\hline Handfield (2019) ${ }^{4}$ & $\begin{array}{l}\text { Analytical capabilities, customer } \\
\text { visibility, trusting relationship }\end{array}$ & $\begin{array}{l}\text { IoT technology, variety of data } \\
\text { sources, real time analytics. }\end{array}$ \\
\hline $\begin{array}{l}\text { Hasselblatt, Huikkola, } \\
\text { Kohtamäki, and Nickell } \\
(2018)^{2}\end{array}$ & $\begin{array}{l}\text { Preventive maintenance, product } \\
\text { safety, reduced operating costs and } \\
\text { information gathering to improve } \\
\text { solution development }\end{array}$ & $\begin{array}{l}\text { Development of digital business } \\
\text { model and solution platform, value } \\
\text { selling and value delivery, business } \\
\text { intelligence capabilities }\end{array}$ \\
\hline $\begin{array}{l}\text { Kowalkowski, Gebauer, } \\
\text { Kamp, and Parry }(2017)^{4}\end{array}$ & $\begin{array}{l}\text { Service viability } \\
\text { Löfberg and Akesson }(2018)^{2}\end{array}$ & $\begin{array}{l}\text { Process optimization, product } \\
\text { condition feedback } \\
\text { sources }\end{array}$ \\
\hline March and Scudder $(2019)^{1}$ & $\begin{array}{l}\text { Predictive maintenance } \\
\text { IoT technology, various data } \\
\text { sources }\end{array}$ \\
\hline
\end{tabular}




\begin{tabular}{|c|c|c|}
\hline Paiola and Gebauer $(2020)^{2}$ & $\begin{array}{l}\text { Asset efficiency, uptime } \\
\text { assurances, preventive mainentance }\end{array}$ & $\begin{array}{l}\text { IoT technology, installed base, } \\
\text { distributor relationships }\end{array}$ \\
\hline Rymaszewska et al. (2017)² & $\begin{array}{l}\text { Increased operational reliability, } \\
\text { minimize non-planned } \\
\text { interruptions, reduce maintenance } \\
\text { cost, improved asset utilisation, } \\
\text { extended product life cycle, } \\
\text { operations optimisation, } \\
\text { maintenance support }\end{array}$ & $\begin{array}{l}\text { IoT technology, various data } \\
\text { sources }\end{array}$ \\
\hline Spring and Araujo (2017) & $\begin{array}{l}\text { Real-time monitoring, optimised } \\
\text { end of life considerations }\end{array}$ & Data analytics \\
\hline Suppatvech et al. (2019) ${ }^{3}$ & $\begin{array}{l}\text { Operational contribution: } \\
\text { responsive \& proactive } \\
\text { maintenance, optimisation of } \\
\text { operations, remote control, } \\
\text { autonomous management, track } \\
\text { and report, realtime information, } \\
\text { remotely monitor customer's usage } \\
\text { behaviour; Strategic contribution: } \\
\text { reduce overall transaction costs; } \\
\text { enable additional functionalities, } \\
\text { enable new core functionalities }\end{array}$ & $\begin{array}{l}\text { Privacy \& data security, } \\
\text { stakeholder collaboration, new } \\
\text { forms of customer interaction, } \\
\text { digital skills, development of } \\
\text { innovative offerings }\end{array}$ \\
\hline $\begin{array}{l}\text { Turunen, Eloranta, and } \\
\text { Hakanen }(2018)^{2}\end{array}$ & $\begin{array}{l}\text { Process and production } \\
\text { optimization }\end{array}$ & $\begin{array}{l}\text { IoT technology, various data } \\
\text { sources, simulation tools }\end{array}$ \\
\hline
\end{tabular}

